Research Paper:

\title{
Multiple Sclerosis Walking Scale-12 (MSWS-12) and its Relationship With Fatigue in People With Multiple Sclerosis
}

\author{
Fatemeh Motaharinezhad $^{1,2}$ (D), Shahriar Parvaneh ${ }^{3 *}$ (D) , Setareh Ghahari ${ }^{3}$ (D) \\ 1. Neuromuscular Rehabilitation Research Center, Semnan University of Medical Sciences, Semnan, Iran. \\ 2. Department of Occupational Therapy, School of Rehabilitation, Iran University of Medical Sciences, Tehran, Iran. \\ 3. School of Rehabilitation Therapy, Queen 's University, Kingston, Canada.
}

\section{(C)(®)}

*This work has been published under CC BY-NC-SA 4.0 license.

Article info:

Received: 01 Aug 2020

Accepted: 02 Nov 2020

Available Online: 01 Dec 2020

Funding

This research did not receive any specific grant from funding agencies in the public, commercial, or not-for-profit sectors.

Conflict of interest

The authors declared no conflict of interest.

\section{ABSTRACT}

Background and Objectives: Walking disorder is one of the most important manifestations of multiple sclerosis (MS), and indicates the progression of the disease. Fatigue and walking are considered as key symptoms affecting the patient's quality of life. Therefore, this study aimed to investigate the relationship between walking status and fatigue, in people with MS.

Methods: A total number of 60 Iranian patients with MS completed the Persian version of the Multiple Sclerosis Walking Scale-12 (MSWS-12), the Modified Fatigue Impact Scale, and the Hospital Anxiety and Depression Scale. Data were analyzed using SPSS V. 20 software. The multivariate correlation and linear regression analyses were conducted to investigate the relationship between fatigue, anxiety, depression, demographic characteristics, and MSWS-12 scores.

Results: Gait problems were observed in $46.7 \%$ of the study participants. Also, the MSWS- 12 scores were significantly associated with fatigue severity $(\mathrm{P}=0.001)$, in these patients. Moreover, depression, cognitive status, anxiety, and gait status were the most important factors affecting fatigue.

Conclusion: According to the present results, the presence of depression, cognitive problems, anxiety, and gait disorders are the most important factors affecting fatigue, in patients with MS.

Keywords: Multiple Sclerosis, Walking, Fatigue

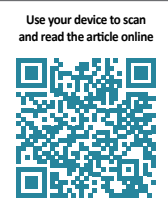

Cite this article as Motaharinezhad F, Parvaneh Sh, Ghahari S. Multiple Sclerosis Walking Scale-12 (MSWS-12) and its Relationship With Fatigue in People With Multiple Sclerosis. Function and Disability Journal. 2020; 3:53-60. http://dx.doi.org/10.32598/fdj.3.10

http://dx.doi.org/10.32598/fdj.3.10

* Corresponding Author:

Shahriar Parvaneh, PhD.

Address: School of Rehabilitation Therapy, Queen `s University, Kingston, Canada.

Tel: +98 (912) 1004187

E-mail:sh_parvaneh@yahoo.com
\What is "already known" in this topic:

Walking impairment can indicate disease progression and severity of disability in patients with $M S$. Thus, evaluation of walking ability and motor state is essential for the treatment and rehabilitation of these patients.

$\rightarrow$ What this article adds:

Evaluation of walking with MSWS-12 scores indicates significant association with fatigue severity. 


\section{Introduction}

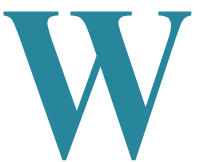

alking impairment is a major manifestation of multiple sclerosis (MS) [1]. Also, the cerebellum is one of the most common sites involved in MS; this involvement is associated with symptoms, such as balance, speech, and walking impairments, which are related to a reduced quality of life among these patients [2]. Since walking impairment can indicate disease progression and lead to disability, the evaluation of walking ability and motor state is essential for the treatment and rehabilitation of patients with MS [1]. These impairments are often objectively evaluated using performance-based instruments, such as T25FW and 6MW [3]. Moreover, some studies have used validated scales, such as the Rivermead Mobility Index and other well-known scales to examine walking ability [4]. However, these instruments assess a major part of the daily functioning of patients and do not specifically examine the effects of the disease on walking indices. The Multiple Sclerosis Walking Scale-12 (MSWS-12) is a 12-item instrument assessing the walking ability of MS patients, in the past two weeks; this scale is also used for patients with other neurological conditions. Initially, the MSWS-12 was designed and evaluated in the college of neurology [5]. This study aimed to examine the relationship between walking impairment (assessed with MSWS-12) and fatigue; this relationship has not been widely examined, despite the high prevalence of both symptoms.

Studies have shown that $85 \%$ of patients with MS suffer from motor and walking impairments [6, 7]. Besides, about $50 \%$ of patients with MS experience disease relapse and progression and lose the ability to walk independently, 15 years after the diagnosis [7]. Fatigue is another prevalent symptom in these patients and is reported in $70 \%$ to $90 \%$ of MS patients [8]. However, few studies have investigated the relationship between walking and fatigue in people with MS. Moriss examined the changes in walking and fatigue in the time between morning and evening; the results showed that fatigue was increased in the patients with MS, while the walking pattern did not change. Still, the stride length and walking speed were reduced as fatigue increased [6]. In their respective studies, Kelleher and Pearson introduced walking impairment as the outcome of the degree of the severity of some MS symptoms, such as fatigue, spasticity, ataxia, and balance disorders [9, 10]. Also, using 6MW and $12 \mathrm{MW}$ scales, Burschka showed that walking speed is significantly correlated with fatigue severity, also, the increase of fatigue severity is associated with the decrease of walking speed in patients [11]. However, no study has examined the relationship between walking impairment (based on Walk-12) and fatigue. Fatigue and walking impairments are considered as key symptoms affecting the quality of life and independence of MS patients, thus, the present study explored the relationship between walking impairment and fatigue.

\section{Materials and Methods}

\section{Design and participants}

This descriptive cross-sectional study was part of a research project on the translation and localization of the Comprehensive Fatigue Assessment Battery for Multiple Sclerosis [12]. The study sample included 60 patients with MS who had visited the Neuromuscular Rehabilitation Research Center, Semnan City, Iran, from 2014 to 2015 . The patients had received a definitive diagnosis of MS, based on the McDonald diagnostic criteria; aged 18 to 60 years; and had the minimum required literacy skills. Also, the exclusion criteria were the score of over 22 on the Mini-Mental State Examination (MMSE), ie, mild cognitive impairment; the MS relapse experience in the course of the study; and the existence of any diseases (neurological, rheumatological, or orthopedic) with fatigue as a symptom. Based on the estimations of previous studies, the sample size for the main study was estimated at 54, considering a 95\% confidence level, a test power of $85 \%$, and the minimum correlation of 0.4 . Considering the risk of attrition, a sample of 60 patients was included in the present study.

\section{Measures}

The questionnaires used were a demographic information questionnaire (age, sex, marital status, occupation, the level of education, the type of the disease, the duration of the disease, comorbidities, and medications), the Walk-12, the Hospital Anxiety and Depression Scale (HADS), and the Modified Fatigue Impact Scale (MFIS)

The Walk-12 is a 12 -item scale. Each item includes five options and receives a score of 1 ("not at all") to 5 ("extremely"). Higher scores indicate the higher impact of the disease on walking. Finally, the score of walking ability falls into a 48-point range with the minimum and maximum scores of 12 and 60, respectively [5]. Walk-12 can be a valuable and useful guide for the evaluation and treatment of walking in patients with MS [13] and has been validated in Iran [14]. 
The MFIS has been developed based on the Fatigue Impact Scale and includes 21 questions in three dimensions of physical, cognitive, and social [15]. The questions are scored based on five items, ranging from 0 ("never") to 4 ("almost always"). A total score of 0 shows the absence of fatigue, and the maximum score of 84 indicates severe fatigue. The Persian version of MFIS is structurally and conceptually sound and has optimal validity (total scale content validity index of 0.85 ) and reliability (internal consistency with a Cronbach's alpha of 0.953) [16].

The HADS evaluates psychiatric disorders and parallelly assesses depression and anxiety in out-patients. The reliability and validity of this scale have been examined in adult out-patients with severe medical pathology; the results have confirmed the good internal consistency of the subscales [17]. Each subscale comprises seven questions. Each question includes four options and is scored on a four-point ordinal scale from 0 to 3 , with higher scores indicating more severe mood disorder. Also, the score ranges of 0 to 7,8 to 10 , and 11 to 21 indicate the lack of depression (normal mood level), borderline case, and depression, respectively [17]. The reliability and validity of HADS have been examined on 261 Iranian patients with depression and anxiety. The findings showed that HADS has optimal reliability, validity, and internal consistency $(\mathrm{r}=0.81, \mathrm{P}<0.001$; alpha $=0.91)$, and holds sufficient validity for use in the Iranian clinical population [18].

The MMSE is a practical instrument for the evaluation, documentation, and follow-up of patients' cognitive functioning throughout their lifetime. The reliability and validity of the Persian version of MMSE have been investigated in the elderly population [19]. This test includes 30 questions in six domains of orientation, registration, attention and calculation, recall, language, and the ability to follow simple commands [20].

\section{Data analysis}

The obtained data were analyzed in SPSS V. 20. The distribution of the demographic data was examined by descriptive statistics, including frequency, mean, and standard deviation. The relationships between Walk-12 scores, fatigue, anxiety, depression, and the other variables were assessed with the Spearman correlation test. Besides, a multivariate stepwise backward linear regression analysis was performed to check the relationship between fatigue and walking ability, in the patients. Moreover, the relationship between Walk-12 scores, anxiety, depression, and demographic characteristics (age, the type of the disease, and the duration of the disease) and the fatigue score was investigated.

\section{Results}

A total number of 60 patients with MS (52 women and $8 \mathrm{men}$ ) complaining of fatigue were included in the study. The Mean \pm SD age of the study sample was $35 \pm 6.68$ years. Also, the Mean \pm SD duration of MS was $5 \pm 3.62$ years, with the minimum and maximum of 1 and 17 years, respectively. Table 1 presents the demographic characteristics of the participants.

The walking problems were observed in $46.7 \%$ of the participants, based on Walk-12. Also, a significant rela-

Table 1. Demographic characteristics of the participants $(N=60)$

\begin{tabular}{|c|c|c|}
\hline \multicolumn{2}{|c|}{ Variables } & \multirow{2}{*}{$\begin{array}{l}\text { No. (\%) } \\
52(87)\end{array}$} \\
\hline & Female & \\
\hline Sex & & \\
\hline & Male & $8(13)$ \\
\hline \multirow{5}{*}{ Type of the disease } & Relapsing-remitting & $37(62)$ \\
\hline & Primary-progressive & $3(5)$ \\
\hline & Secondary-progressive & $1(2)$ \\
\hline & Progressive-relapsing & $5(8)$ \\
\hline & Unknown & $14(23)$ \\
\hline \multirow[b]{2}{*}{ Cognitive level (based on MMSE) } & Mild cognitive impairment (score range, 22-26) & $15(25)$ \\
\hline & Norm & $45(75)$ \\
\hline
\end{tabular}

MMSE: Mini-Mental State Examination. 
Table 2. Correlation between fatigue, anxiety, depression and walk-12

\begin{tabular}{cccc}
\hline variables & Mean \pm SD & ICC & $<0.0001$ \\
\hline MFIS & $30.22 \pm 20.14$ & 0.518 & $<0.002$ \\
Depression (HADS) & $5.69 \pm 4.02$ & 0.395 & $<0.042$ \\
Anxiety (HADS) & $8.25 \pm 4.90$ & 0.266 & \\
\hline
\end{tabular}

HADS: Hospital Anxiety Depression Scale; MFIS: Modified Fatigue Impact Scale; MSWS: Multiple Sclerosis Walking Scale; ICC: Intra-class Correlation Coefficient.

tionship was found between the Walk-12 score and the severity of fatigue $(\mathrm{P}=0.001)$ (Table 2$)$. Table 3 presents the relationship between the Walk-12 score and the demographic characteristics of the patients. Moreover, anxiety and depression were significantly and directly related to the Walk-12 and fatigue scores, in the patients. Depression was the most important factor affecting fatigue (Table 4). The other variables, e.g. cognitive status, anxiety, and walking ability were ranked next and showed a significant effect in the statistical analysis.

\section{Discussion}

The walking ability as a motor index plays a key role in quality of life and affects fatigue status, in patients with MS. Therefore, the severity of walking impairment is a major factor in examining the degree of disease progression. First, Hobart developed the 12-item scale to ex- amine the effect of MS on walking ability and promote the assessment of walking ability in these patients. It is considered as an instrument with optimal validity and reliability [5], and suitable for the examinations of walking ability. Previous studies in Iran have shown that the Persian version of Walk-12 is appropriate for evaluating the walking ability of patients with MS [14].

The MSWS-12 aimed to investigate the effect of MS on patients' walking ability [5]. Kieseier examined walking impairment evaluation in these patients to explore the clinical application of specific measurements of walking in MS. The scores of performance-based tests often used for impairment evaluation are strongly associated with the Walk-12 scores [21]. Researchers do not regard MSWS-12 as an MS-specific measure, because symptoms observed in MS are not limited to MS and appear in many other neurological diseases. Holland

Table 3. Correlation between demographic variables and walk-12

\begin{tabular}{ccc}
\hline Variables & Correlation Coefficient & P \\
\hline MS Duration $(y)$ & 0.005 & $\mathrm{P}=0.577$ \\
Age & 0.198 & $\mathrm{P}=0.136$ \\
Cognition (MMSE score) & 0.028 & $\mathrm{P}=0.039$
\end{tabular}

MMSE: Mini-Mental State Examination.

Table 4. Factors affecting walking ability, based on stepwise (backward) regression analyses

\begin{tabular}{ccc}
\hline Variables & Beta (F) & R Square \\
\hline Fatigue & $0.527(0.001)$ & $0.278^{*}$ \\
Depression & $0.477(0.015)$ & $0.506^{* *}$ \\
Cognition & $0.341(0.008)$ & 0.622 \\
Anxiety & $0.527(0.001)$ & 0.707 \\
\hline
\end{tabular}

* This value shows the effect of fatigue score on walking ability; ${ }^{*}$ This value shows the effect of the sum of fatigue and depression scores on walking ability. In the rest of the table, the values in this column include the effect of the sum of the scores in the previous rows of the respective column. 
examined the suitability of this scale for walking ability measurement in neurological diseases. This researcher stated that other diseases affect the walking ability and cause limitations; he also highlighted that a generalized instrument can provide valuable insights into patients' perception in clinical studies [22]. Walking ability is a general variable; the 12 items in MSWS-12 examine the walking problems of patients with neurological diseases.

The present study examined the relationship between Walk-12 and fatigue scores. The fatigue scores are strongly correlated with walking scores in patients with MS; as fatigue is increased, the walking ability is further affected. In other words, the walking ability is a factor affecting fatigue in patients with MS. Few studies have investigated the relationship between walking and fatigue in MS patients. Furthermore, these limited studies have been indirectly demonstrated that motor impairments, including walking impairment, are increased with fatigue, in patients $[6,22]$. However, a careful examination of the variables in this study showed that depression, cognitive status, anxiety, and walking ability affect the fatigue severity in patients with MS. Also, depression was the most effective factor in fatigue; this effect has been examined and confirmed in different studies [23-25]. In some of these studies, the patients' cognitive status has been also introduced as the second factor affecting fatigue [25].

We used the data as a secondary study; all the examined patients suffered from fatigue. It is recommended to examine this relationship in MS patients without fatigue. Also, It is suggested that future studies compare the effect of fatigue on walking ability in other neurological diseases. Thus, measures can be taken for providing more expansive treatment of patients with neurological diseases who have walking impairment and chronic fatigue.

\section{Conclusion}

This study introduced a walking ability evaluation instrument with high reliability, replicability, and responsiveness to be used by healthcare providers and researchers in Iran. The objective was to assess the relationship between fatigue and walking impairment assessed with this instrument. Based on the results, depression, cognitive problems, anxiety, and walking impairment are among the most important factors affecting fatigue.

\section{Ethical Considerations}

\section{Compliance with ethical guidelines}

This study was approved by the Research Ethical Committee of the University of Social Welfare and Rehabilitation Sciences (Code: USWR.REC.1392.161).

Funding

This research did not receive any specific grant from funding agencies in the public, commercial, or not-for-profit sectors.

Authors' contributions

All authors contributed equally in preparing all parts of the research.

\section{Conflict of interest}

The authors declared no conflict of interest.

\section{Acknowledgments}

The authors would like to thank all the staff and colleagues of the Neuromuscular Rehabilitation Research Center in Semnan and the MS Association of Semnan.

\section{References}

[1] Martin CL, Phillips BA, Kilpatrick TJ, Butzkueven H, Tubridy $\mathrm{N}$, McDonald E, et al. Gait and balance impairment in early Multiple Sclerosis in the absence of clinical disability. Mult Scler. 2006; 12(5):620-8. [DOI:10.1177/1352458506070658] [PMID]

[2] Coleman CI, Sidovar MF, Roberts MS, Kohn C. Impact of mobility impairment on indirect costs and healthrelated quality of life in Multiple Sclerosis. PLoS One. 2013; 8(1):e54756. [DOI:10.1371/ journal.pone.0054756] [PMID] [PMCID]

[3] Kieseier BC, Pozzilli C. Assessing walking disability in Multiple Sclerosis. Mult Scler. 2012; 18(7):914-24. [DOI:10.1177/1352458512444498] [PMID]

[4] Samaei A, Bakhtiary AH, Moghimi J, Khani MM. [Reliability and validity of the Persian version of the rivermead mobility scale in Multiple Sclerosis patients (Persian)]. Koomesh. 2014; 15(4):575-83. http://koomeshjournal.semums.ac.ir/article-1-2314-fa.html

[5] Hobart JC, Riazi A, Lamping DL, Fitzpatrick R, Thompson AJ. Measuring the impact of MS on walking ability: The 12-Item MS Walking Scale (12-MSWS). Neurology. 2003; 60(1):31-6. [DOI:10.1212/WNL.60.1.31] [PMID]

[6] Morris ME, Vowels L, Dodd K. Changes in gait and fatigue from morning to afternoon in people with Multiple Sclerosis. J Neurol Neurosurg Psychiatry. 2002; 72(3):361-5. [DOI:10.1136/ jnnp.72.3.361] [PMID] [PMCID] 
[7] Weinshenker BG, Bass B, Rice GP, Noseworthy J, Carriere W, Baskerville J, et al. The natural history of Multiple Sclerosis: A geographically based study: I. Clinical course and disability. Brain. 1989; 112(1):133-46. [DOI:10.1093/brain/112.1.133] [PMID]

[8] Rottoli M, La Gioia S, Frigeni B, Barcella V. Pathophysiology, assessment and management of Multiple Sclerosis fatigue: An update. Expert Rev Neurother. 2017; 17(4):373-9. [DOI:10.1080/14737175 .2017.1247695] [PMID]

[9] Kelleher KJ, Spence W, Solomonidis S, Apatsidis D. Ambulatory rehabilitation in Multiple Sclerosis. Disabil Rehabil. 2009; 31(20): 1625-32. [DOI:10.1080/09638280902751931] [PMID]

[10] Pearson OR, Busse ME, Van Deursen RW, Wiles CM. Quantification of walking mobility in neurological disorders. QJM: Inte J Med. 2004; 97:463-75. [DOI:10.1093/qjmed/hch084] [PMID]

[11] Burschka JM, Keune PM, Menge U, Hofstadt-van Oy U, Oschmann P, Hoos O. An exploration of impaired walking dynamics and fatigue in Multiple Sclerosis. BMC Neurol. 2012; 12(1):161. [DOI:10.1186/1471-2377-12-161] [PMID] [PMCID]

[12] Motaharinezhad F, Parvaneh S, Ghahari S, Bakhtiary AH, Biglarian A, Sokhangoye Y, et al. [Validation of Persian version of Comprehensive Fatigue Assessment Battery for Multiple Sclerosis (CFABMS) (Persian)]. J Mazandaran Univ Med Sci. 2015; 25(131):56-66 http://jmums.mazums.ac.ir/article-1-6571-fa.html

[13] Learmonth YC, Dlugonski DD, Pilutti LA, Sandroff BM, Motl RW. The reliability, precision, and clinically meaningful change of walking assessments in Multiple Sclerosis. Mult Scler. 2013; 19(13): 1784-91. [DOI:10.1177/1352458513483890] [PMID]

[14] Ansari NN, Naghdi S, Mohammadi R, Hasson S. Multiple Sclerosis Walking Scale-12, translation, adaptation and validation for the Persian language population. Gait Posture. 2015; 41(2):420-4. [DOI:10.1016/j.gaitpost.2014.11.003] [PMID]

[15] Mathiowetz V. Test-retst reliability and convergent validity of the fatigue impact scale for persons with Multiple Sclerosis. Am J Occup Ther. 2003; 57(4):389-95. [DOI:10.5014/ajot.57.4.389] [PMID]

[16] Heidari M, Salehi M, Nabavi SM. [Survey validity of translation for persian and cultural adaptation of Fatigue Impact Scale (FIS) questionnaire in pultiple sclerosis patients in Iran (Persian)]. J Modern Rehabil. 2012; 6(3):20-9. http://mrj.tums.ac.ir/article-1-24-fa.html

[17] Herrero MJ, Peri JM, De Pablo J, Pintor L, Bulbena A. A validation study of the Hospital Anxiety and Depression Scale (HADS) in a spanish population. Gen Hosp Psychiatry. 2003; 25(131):277-83. [DOI:10.1016/S0163-8343(03)00043-4]

[18] Kaviani H, Seyfourian H, Sharifi V, Ebrahimkhani N. [Reliability and validity of Anxiety and Depression Hospital Scales (HADS) Iranian patients with anxiety and depression disorders (Persian)] Tehran Univ Med J. 2009; 67(5):379-85. https://tumj.tums.ac.ir/ article-1-453-fa.pdf

[19] Foroughan M, Jafari Z, Shirin Bayan P, Ghaem Magham Farahani Z, Rahgozar M. [Validation of Mini- Mental State Examination (MMSE) in the elderly population of Tehran (Persian)]. Adv Cog Sci. 2008; 10(2):29-37. http://icssjournal.ir/article-1-422-fa.html

[20] Cockrell JR, Folstein MF. Mini-Mental State Examination (MMSE). Psychopharmacol Bull. 1988; 24(4):688-92. https://pubmed.ncbi.nlm.nih.gov/3249771/

[21] Kieseier BC, Pozzilli C. Assessing walking disability in Multiple Sclerosis. Mult Scler J. 2012; 18(7):914-24 [DOI:10.1177/1352458512444498] [PMID]
[22] Holland A, O’Connor RJ, Thompson AJ, Playford ED, Hobart JC. Talking the talk on walking the walk A 12-item generic walking scale suitable for neurological conditions? J Neurol. 2006; 253(12):1594-602. [DOI:10.1007/s00415-006-0272-2] [PMID]

[23] Kaynak H, Altintaş A, Kaynak D, Uyanik Ö, Saip S, Ağaoğlu J, et al. Fatigue and sleep disturbance in multiple sclerosis. Eur J Neurol. 2006; 13(12):1333-9. [DOI:10.1111/j.1468-1331.2006.01499.x] [PMID]

[24] Feinstein A, Magalhaes S, Richard J, Audet B, Moore C. The link between Multiple Sclerosis and depression. Nature Rev Neurol. 2014; 10(9):507-17. [DOI:10.1038/nrneurol.2014.139] [PMID]

[25] Motaharinezhad F, Parvaneh Sh, Bakhtiary AH, Alizadeh N, Ghahari S. [The effect of mood and cognition on relationship between sleep disturbances and fatigue in people with Multiple Sclerosis (Persian)]. Koomesh. 2016; 19:613-9. http://eprints.semums. ac.ir/1012/1/Koomesh-v17n3p613-en.pdf 
MSWS_12 برسشنامه وضعيث راه رفتن و أرثباط آن با خستئى در بيماران مبثلا به مولتييل اسكلروزيس

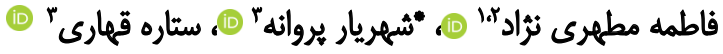 \\ 1. مركز تحقيقات توانبخشى عصبى عضلانى، دانشُكاه علوم بزّشكى سمنان، سمنان، ايران.

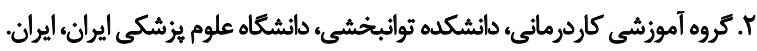

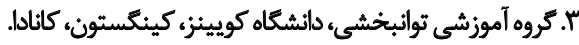

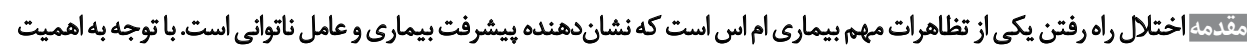

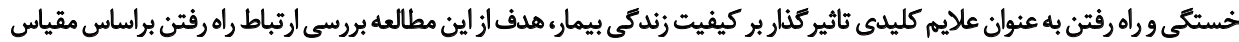









متغيره استفاده شدر.

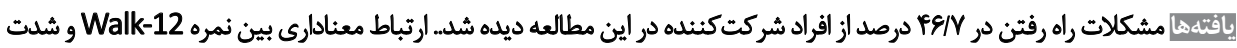



موثر بر خستكى بودئد.

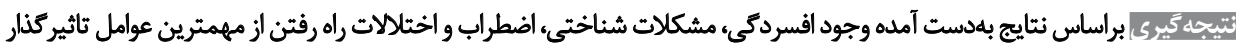

برخستكى هستئد.

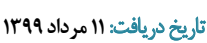

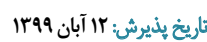
تاريخ انتشار: ؟؟؟ تارئ

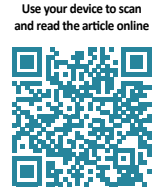

Clte this article as Motaharinezhad F, Parvaneh Sh, Ghahari S. Multiple Sclerosis Walking Scale-12 (MSWS-12) and its Relationship With Fatigue in People With Multiple Sclerosis. Function and Disability Journal. 2020; 3:??. http://dx.doi.org/10.32598/ fdj. 3.10

doi) $h$ htp://dx.doi.org/10.32598/fdj.3.10

كليدوازهها:

مولتييل اسكلروزيس،

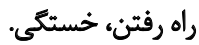


This Page Intentionally Left Blank 